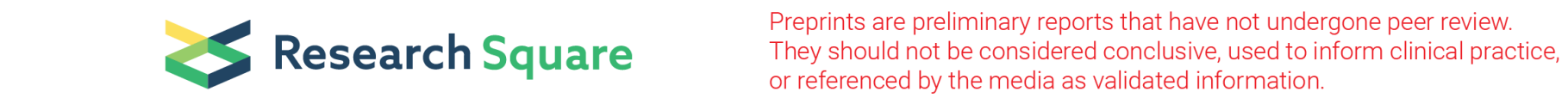

\title{
Defining the minimal effective volume and amount of lidocaine to perform a femoral nerve block under ultrasound control
}

Valery Piacherski ( $\sim$ pechersky.v@yandex.ru )

Mogilev Regional Hospital https://orcid.org/0000-0002-6237-8063

Aliaksei Marachkou

Mogilev Regonal Hospital

Research article

Keywords: femoral nerve blockade, lidocaine, minimum effective dose, ultrasound control, minimum effective volume, local anesthetic

Posted Date: January 2nd, 2020

DOI: https://doi.org/10.21203/rs.2.15746/v2

License: () (7) This work is licensed under a Creative Commons Attribution 4.0 International License. Read Full License 


\section{Abstract}

Background

The application of the combination of local anesthetics $(L A)$ in some parts of the body increases the amount of LA and plasma concentration. The aim of our research was to define the minimal effective volume and amount of lidocaine with added adrenaline $(1: 200,000)$ to perform a femoral nerve block under ultrasound control and with neurostimulation.

Methods

Femoral nerve blockade was performed with the following lidocaine solutions: $0.75 \%-10 \mathrm{ml}, 7.5 \mathrm{ml} ; 1 \%-20 \mathrm{ml}, 15 \mathrm{ml}, 10 \mathrm{ml}, 7.5 \mathrm{ml}, 5 \mathrm{ml} ; 1.5 \%-5 \mathrm{ml}, 4 \mathrm{ml} ; 2 \%-5$ $\mathrm{ml}, 4 \mathrm{ml} ; 3 \%-5 \mathrm{ml}, 4 \mathrm{ml}, 3 \mathrm{ml} ; 4 \%-5 \mathrm{ml}, 4 \mathrm{ml}, 3 \mathrm{ml}, 2.5 \mathrm{ml}$. All blocks were performed with added adrenaline $(1: 200,000)$. In all, 181 blocks of the femoral nerve, in combination with sciatic nerve blocks, were carried out with the help of the electrostimulation of peripheral nerves, and under ultrasound. The quality of motor and sensory blocks was assessed after $45 \mathrm{~min}$ of administration of the femoral nerve block.

Results

A total of 181 femoral nerve blocks, in combination with sciatic nerve blocks, were used via the help of electrostimulation of the peripheral nerves (EPN), and under ultrasound (US) control. The femoral nerve blockade was effective with the following lidocaine solutions: $0.75 \%-10 \mathrm{ml}(75 \mathrm{mg}) ; 1 \%-20 \mathrm{ml}, 15 \mathrm{ml}, 10 \mathrm{ml}$, $7.5 \mathrm{ml}$ (75mg); $1.5 \%-5 \mathrm{ml}(75 \mathrm{mg}) ; 2 \%-5 \mathrm{ml}$ (100 mg); $3 \%-5 \mathrm{ml}$ (150mg); $4 \%-5 \mathrm{ml}$ (200mg). Femoral blockade was ineffective when using the following solutions of lidocaine: $0.75 \%-7.5 \mathrm{ml}(56.25 \mathrm{mg}) ; 1 \%-5 \mathrm{ml}(50 \mathrm{mg}) ; 1.5 \%-4 \mathrm{ml}(60 \mathrm{mg}$, No spread along the entire circumference of the nerve - NSAECN); $2 \%-4$ $\mathrm{ml}$ (80mg, NSAECN); 3\% - 4ml (120mg NSAECN), $3 \mathrm{ml} ; 4 \%$ - $4 \mathrm{ml}$ (160 mg, NSAECN), 3 ml, $2.5 \mathrm{ml}$.

Conclusion

For a complete motor and sensory block of the femoral nerve: the minimum effective volume of local anesthetics was $5 \mathrm{ml}$; and the minimum effective amount of lidocaine was $75 \mathrm{mg}$. A complete block of the femoral nerve was achieved only with the spreading of local anesthetic along the whole circumference of the femoral nerve.

\section{Background}

Femoral nerve blocks in combination with blockade of sciatic nerve are applied in order to perform anesthesia while operating on the knee joint, shin, and foot. The application of the combination of local anesthetics (LA) in some parts of the body increases the amount of LA and plasma concentration [1, 2]. Cuvillon et al., stated that, even when administered with bupivacaine and ropivacaine within the recommended doses of the LA plasma concentration, that some patients may still exceed the safe level, and that this is dependent upon other different conditions[2]. Earlier it was also noticed that the toxic effect of LA on the cardiovascular system was registered even for usual LA plasma concentrations[3, 4]. In consideration of these data, it is relevant to apply small doses of local anesthetics in order to increase the safety of the peripheral nerve blocks, especially while performing a combined blockage of the sciatic and femoral nerves.

Danelli et al.[5] has indicated that the $95 \%$ effective dose (ED95) for $1.5 \%$ mepivacaine is $14 \mathrm{ml}$ in order to block the sciatic nerve. Latzke et al. [6] attempted to define the minimal efficient dose of mepivacaine required to perform a sciatic nerve block, and indicated that the minimal efficient dose was $0.10 \mathrm{ml} \mathrm{mm}^{-2}$ (from 2.8 to $10.2 \mathrm{ml}$ of $1.5 \%$ mepivacaine). Other research has suggested that the minimal efficient volume and amount of lidocaine required to carry out a sciatic nerve block was $5 \mathrm{ml}$ ( $3 \%$ and $4 \%)$, and $125 \mathrm{mg}(12.5 \mathrm{ml}, 1 \%$ solution), respectively [ 7 ]. The minimal efficient volume of $0.75 \%$ ropivacaine has been set for the sciatic nerve block under ultrasound control in the gluteal area [8].

The number of publications dedicated to determining the minimal amount and volume of local anesthetics required to block the femoral nerve under ultrasound control, is small. Casati et al. have stated that the ED 95 required to block the femoral nerve for $0.5 \%$ ropivacaine is $22 \mathrm{ml}$ [9].

Taha et al.[10] have demonstrated in their research that $15 \mathrm{ml}$ of $0.93 \%$ lidocaine is necessary for $89 \%$ efficacy of the femoral nerve block. Considering the acquired data for the sciatic nerve block [7] this avenue of research needs further investigations. As the authors mentioned in their paper, the minimal efficient volume of lidocaine was not defined[10]. It has also not been revealed how the combinations of the different concentrations and volumes of lidocaine solutions affects the efficacy of the femoral nerve blocks.

The aim of our research was to define the minimal efficient volume and amount of lidocaine with added adrenaline $(1: 200,000)$ necessary to perform the femoral nerve blocks under ultrasound control, and with neurostimulation.

\section{Materials And Methods}

The research was carried out with the permission of the Ethics Committee. All patients gave informed consent to participate in the study and the upcoming type of anesthesia. 
The criteria for patient inclusion were: surgical indication requiring anesthesia maintenance, patient's written consent about the type of anesthesia and possible complications of regional anesthesia. The exclusion criteria were: patient's refusal of application for the proposed form of anesthesia, patients younger than 18 years, patients weighing less than $50 \mathrm{~kg}$, a physical status score of more than 3 determined by the American Society of Anesthesiologists (ASA), a history of allergic reactions to the drugs used, coagulopathies, infections of the skin at the injection site, neurological or neuromuscular diseases, severe liver diseases or kidney failures, and an inability to cooperate with the patient.

With the aim of premedication, $0.5-0.8 \mathrm{mg}$ of atropine and $10 \mathrm{mg}$ of diphenhydramine were injected intramuscularly $20-30 \mathrm{~min}$ prior to the administration of the block. A venous approach via peripheral vein catheterization was taken for all patients. Peripheral capillary oxygen saturation (SPO2), electrocardiography (ECG) and noninvasive measurement of blood pressure were monitored.

A total of 181 femoral nerve blocks, in combination with sciatic nerve blocks, were used via the help of electrostimulation of the peripheral nerves (EPN), and under ultrasound (US) control. In order to provide visualization of the ultrasound image, a transducer frequency of 7.5-10 MHz was used. Following the ultrasound visualization of the femoral nerve, a $100 \mathrm{~mm}$ insulated injection needle (Stimuplex ${ }^{\circledR}$, B Braun, Melsungen, Germany) was connected to the nerve stimulator (HNS 11, B Braun, Melsungen, Germany). Under ultrasound visualization guidance, the needle of the electronic nerve stimulator (current strength, $0.4 \mathrm{MA}$ ) was positioned at the femoral nerve (in plane) from its lateral side at a slightly superior position. A marker for LA introduction was the visualization of the needle end near the femoral nerve, and a positive muscular response (patellae twitching). Subsequently, the introduction of LA solution was initiated. The position of the needle was corrected 1-2 times according to the type of anesthetic spread. If LA was spreading from the lateral side down to the nerve, then the needle was replaced to the upper point of the femoral nerve and the rest of LA was introduced, and vice versa (Fig.1 and 2). The presence of a complete and incomplete spread of LA along the entire circumference of the nerve was assessed. Correspondingly, if the anesthetic was spreading upwardly, the needle would be downwardly replaced.

All of the blocks were performed by the same anesthesiologist whose operational experience in regional anesthetics was 8 years with an annual average of 600 blocks of the femoral nerve carried out under ultrasound control.

There are several approaches to organize research to define the minimal dose and volume of local anesthetic needed to perform peripheral nerve blocks. The method outlined by Dixon in 1948,10 and its modified version[11,12] has allowed for the definition of the 50\% effective dose (ED50).

Another method had stated that, according to the effective concentration of LA, the following concentration of anesthetic either increases or decreases by $0.1 \%, 10$ thereby indicating that the minimal effective volume of local anesthetic had not been defined. Conversely, one concentration of local anesthetic would be decided upon for use, and prior to investigation, a researcher would choose several LA volumes to perform the blocks [13]. From this, calculation of the ED was possible.

Another method used to determine the minimal amount of LA for several concentrations was by reducing their volumes. The reduction in volume was defined by the anesthesiologist according to the efficacy of the block with regards to the given amount of LA. These data were then listed in a table format. The necessity for further investigation was determined by different groups: the reduction in volume; the decrease or increase in concentration according to earlier results; and for the conveniences of everyday anesthesiology practice. This method allows for the definition of both the minimal effective amount of LA, and for the minimal effective volume of LA (while applying the proven, effective amount of LA)[7]. This method considers a dose and volume to be ineffective if there is a failure to develop a complete block upon introduction of the entire LA volume to the target area (fascial compartment). ED50, and 80\% (ED80) and $90 \%$ (ED90) effective doses were not assessed. Therefore, it is evident that, while performing blocks with LA solution, a complete peripheral block is always produced with an effective amount and volume. If a complete block does not develop, the amount and volume are considered ineffective. This method provides a good basis for recommendations as LA amount and volume are only considered effective when they develop complete blocks of the peripheral nerve.

In our research, we applied the aforementioned method in the search for the minimal effective volume and amount of anesthetic [7]. As a starting point, a concentration of $1 \%$ lidocaine was selected as it is the most widely applied solution for peripheral blocks. Subsequently, depending upon the acquired results, we applied $0.75 \%, 1.5 \%, 2 \%, 3 \%$, and $4 \%$ solutions in volumes that had been defined in accordance with the results of the research. All blocks were performed with adrenaline added $(1: 200,000)$.

The Ethics Committee stated that if there were up to 4 cases of ineffective femoral nerve blocks with the same solution, then the application of this concentration and volume had to be stopped.

The blocks of the sciatic nerve were performed in the gluteal region under ultrasound control with the application of EPN $15 \mathrm{ml}$ of $1 \%$ lidocaine solution.

The quality of motor and sensory blocks was assessed after 45 min of administration of the femoral nerve block. The evaluation of the block was carried out by an anesthesiologist who was not involved in the study, and was blinded to solution that had been applied.

To assess a motor block, a patient was asked to raise their leg in knee extension. If the patient failed to raise their leg in knee extension, then a motor block of the femoral nerve was considered to have successfully developed.

The assessment of the motor block was carried out with the help of the following scale: $++\backslash$ which indicated that movements were completely absent; $+\backslash$ which indicated that movements were partially preserved or were uncoordinated; and $-\backslash$ which indicated that movements were fully preserved.

The stimulus of the needle prick was applied to check the sensory block of the femoral nerve. The area of the patellar, the anterior aspect of the lower one third of the thigh, and the medial aspect of the leg corresponding to the dermatome innervated by the saphenous nerve, were assessed. The assessment of skin

Page $3 / 11$ 
sensitivity was carried out with the help of a similar scale: $++\backslash$ indicating a complete sensory block; $+\backslash$ indicating a partial sensory block, a patient was unable to differentiate between the type of stimuli; and $-\backslash$ indicating that the skin sensitivity was fully preserved.

In consideration of Moayeri N. et al. regarding the possible influence of the correlation between neural and non-neural tissues on the minimal effective dose of anesthetics [14], the cross-sectional area of the femoral nerve after blocking was measured in order to account for the influences of femoral nerve anatomical variations on the minimal effective dose of lidocaine. The measurement was carried out to exclude the possible influence of different cross-sectional areas of the femoral nerve on the development of the block, while applying small doses of local anesthetics.

Statistical data analyses were performed using the program Statistica 7.0. The groups of patients were compared using the non-parametric method of a Kruskal-Wallis ANOVA. The null hypothesis about the absence of differences was accepted at $p$ was greater than 0.05 . If $p$ was less than 0.05 , the null hypothesis was rejected, and the differences between the groups were considered to be statistically significant. A pairwise comparison of the groups was carried out using a non-parametric Mann-Whitney test. The data were expressed as median and quartiles (25th and 75th percentiles). The differences between the groups were evaluated by the complete and incomplete block (indicated above). The frequencies of the binary trait in two unrelated (independent) groups were compared by analyzing the contingency table $(2 \times 2)$. Differences between groups were considered statistically significant at $p<0.05$.

\section{Results}

Of the 181 patients, one patient was excluded. A double trunk of the femoral nerve was noted. This anatomical variation was depicted in an ultrasound image (Fig. 3). While applying the needle, neurostimulator (NS), under ultrasound control, each branch of the femoral nerve responded with patella twitches. Twenty milliliters of $1 \%$ lidocaine solution was introduced. After $45 \mathrm{~min}$, complete sensory and motor blocks had developed.

An additional patient was excluded from the study as an unpremeditated intraneural introduction of 3. 5 ml of 1\% lidocaine solution was noted (Fig. 4). Complete sensory and motor blocks developed. The block ended in $3 \mathrm{~h}$. There were no complications during the nearest and distant postoperative periods.

While measuring the cross-sectional area of the femoral nerve, there were no significant differences between the groups $(p=0.98)$. The cross-sectional area of the femoral nerve in the region of the block was $0.27 \mathrm{~cm} 2$ (range: $0.24-0.3 \mathrm{~cm} 2$ ). In table 1 , the demographic data of the patients are listed, in addition to the measured cross-sectional area of the femoral nerve of each group.

1.Stage $1 \%$ lidocaine.

The femoral nerve blocks of the 15 patients were performed with $20 \mathrm{ml}$ of $1 \%$ lidocaine. In all cases, the blocks were effective (++\++). The amount of lidocaine for the femoral nerve block was $200 \mathrm{mg}$. The solution of local anesthetic had spread in the fascial plane, along the whole circumference of the femoral nerve in all directions. Subsequently, the volume of the $1 \%$ lidocaine solution was decreased to $15 \mathrm{ml}$.

The femoral nerve blocks with $1 \%$ lidocaine in the volumes of 15 and $10 \mathrm{ml}$ (150 and $100 \mathrm{mg}$, respectively) were effective in all cases (Table 2). The volume was then reduced to $7.5 \mathrm{ml}$.

Twenty femoral nerve blocks of the 20 patients with $7.5 \mathrm{ml}$ of $1 \%$ lidocaine solution were performed. All patients had complete blocks of the femoral nerve $(++\backslash++)$. The amount of lidocaine used to block the femoral nerve was $75 \mathrm{mg}$. The solution of local anesthetic had spread into the fascial plane along the whole circumference of the femoral nerve. A decision to decrease the volume of the $1 \%$ lidocaine to $5 \mathrm{ml}$ was made.

The femoral nerve blocks were performed with the adjusted volume of $5 \mathrm{ml}$ of the $1 \%$ lidocaine solution. In consideration of the fact that this dose was considered ineffective $(+\backslash+)$, only 4 patients had such blocks. In this scenario, the amount of lidocaine to block the femoral nerve was 50 mg. The solution of local anesthetic had spread into the fascial plane along the whole circumference of the femoral nerve. Subsequently, according to a decision made by the Ethics Committee, blocks that involved volumes of $5 \mathrm{ml}$, or less, of the $1 \%$ lidocaine solution were not performed.

\section{Stage $0.75 \%$ lidocaine.}

In consideration of the minimal effective amount of lidocaine at the stage " $1 \%$ lidocaine", which was 75 mg, we decided to start performing blocks at this stage with $10 \mathrm{ml}$. Twenty blocks of the femoral nerve of the 20 patients were carried out with $10 \mathrm{ml}$ of $0.75 \%$ lidocaine. All patients had complete blocks of the femoral nerve $(++\backslash++)$. In this scenario, the amount of lidocaine used to block the femoral nerve was $7.5 \mathrm{mg}$. The solution of local anesthetic had spread in the fascial plane along the whole circumference of the femoral nerve. A decision was made to decrease the volume of the $0.75 \%$ lidocaine to $7.5 \mathrm{ml}$.

Consequently, the femoral nerve blocks were administered at an adjusted volume of $7.5 \mathrm{ml}$ of the $0.75 \%$ lidocaine solution. As these blocks were recorded to be ineffective $(+\backslash+)$, only 4 patients had such blocks. The amount of lidocaine used to block the femoral nerve was $56.25 \mathrm{mg}$. The solution of local anesthetic had spread into the fascial plane along the whole circumference of the femoral nerve. Following this, in accordance with the Ethics Committee, blocks that involved volumes of $7.5 \mathrm{ml}$, or less, for the $0.75 \%$ lidocaine solution were not performed.

3.Stage $1.5 \%$ lidocaine.

As the minimal effective amount of lidocaine at the stage " $1 \%$ lidocaine" was $75 \mathrm{mg}$, we decided to start performing the blocks at the stage " $1,5 \%$ lidocaine" with a volume of $5 \mathrm{ml}(75 \mathrm{mg})$. Fifteen femoral nerve blocks had been respectively administered to the 15 patients at a volume of $5 \mathrm{ml}$ of the $1.5 \%$ lidocaine solution. All patients had complete blocks of the femoral nerve $(++\backslash++)$. The solution of local anesthetic had spread into the fascial plane along the whole circumference of the femoral nerve. A decision to decrease the volume of $1.5 \%$ lidocaine to $4 \mathrm{ml}$ was made. 
Consequently, the femoral nerve blocks were performed with an adjusted volume of $4 \mathrm{ml}$ of the $1.5 \%$ lidocaine solution. As these blocks were noted as being ineffective $(+\backslash+)$, only 4 patients had such blocks. The amount of lidocaine used to block the femoral nerve was $60 \mathrm{mg}$. The solution of local anesthetic did not spread into the fascial plane along the whole circumference of the femoral nerve. Following this, in accordance with the Ethics Committee, blocks involved a volume of $4 \mathrm{ml}$, or less, of the $1.5 \%$ lidocaine solution were not performed.

4.Stage $2 \%$ lidocaine.

Considering the fact that at the previous stage, $4 \mathrm{ml}$ volume of lidocaine solution failed to spread throughout the whole circumference of the femoral nerve, and present data further affirmed that a complete block may not develop, 7 we decided to initially use $5 \mathrm{ml}(100 \mathrm{mg})$ of the $2 \%$ solution, then use $5 \mathrm{ml}$ of $2 \%$ lidocaine $(100 \mathrm{mg})$. All patients had complete blocks of the femoral nerve $(++\backslash++)$. The solution of local anesthetic had spread into the fascial plane along the whole circumference of the femoral nerve. A decision was made to decrease the volume of the $2 \%$ lidocaine solution to $4 \mathrm{ml}$.

The femoral nerve blocks were then performed with the adjusted volume of $4 \mathrm{ml}$ of the $2 \%$ lidocaine solution. These blocks were ineffective (+\+) and only 4 patients had such blocks. The amount of lidocaine used to block the femoral nerve was $80 \mathrm{mg}$. The solution of local anesthetic failed to spread in the fascial plane along the entire circumference of the femoral nerve. Subsequently, in accordance with the Ethics Committee, blocks that involved a volume of $4 \mathrm{ml}$, or less, of the $2 \%$ lidocaine solution were not performed.

5.Stage $3 \%$ lidocaine.

The aforementioned reasoning made us commence application of the $3 \%$ lidocaine solution at a volume of 5 ml. Fifteen femoral nerve blocks for the respective 15 patients were carried out at a volume of $5 \mathrm{ml}$ of the $3 \%$ lidocaine. All patients had complete blocks of the femoral nerve (++ $\backslash++)$. The solution of local anesthetic had spread into the fascial plane along the whole circumference of the femoral nerve. We decided to decrease the volume of the $3 \%$ lidocaine to $4 \mathrm{ml}$.

Following this, the femoral nerve blocks were performed with the adjusted volume of $4 \mathrm{ml}$ of the $3 \%$ lidocaine solution. As the blocks were ineffective (+\+), only 4 persons had such blocks. The amount of lidocaine used to block the femoral nerve was $120 \mathrm{mg}$. The solution of local anesthetic failed to spread into the fascial plane along the whole circumference of the femoral nerve. Subsequently, according to the decision of the Ethics Committee, blocks with a volume of $4 \mathrm{ml}$, or less, of the $3 \%$ lidocaine solution were not performed.

Considering the fact that the amount of lidocaine at $120 \mathrm{mg}$ sufficiently exceeded the minimal effective amount of lidocaine at the previous stages, which was $75 \mathrm{mg}$, we decided to reduce the volume of the $3 \%$ lidocaine solution to $3 \mathrm{ml}(90 \mathrm{mg})$ in order to account for this observation. As these blocks were ineffective $(+\backslash+)$, only 4 patients had such blocks. The solution of local anesthetic failed to spread into the fascial plane along the whole circumference of the femoral nerve. Subsequently, according to the decision of the Ethics Committee, blocks with a volume of $3 \mathrm{ml}$, or less, of the $3 \%$ lidocaine solution were not administered.

6.Stage $4 \%$ lidocaine.

In consideration of the data acquired at the previous stages, we applied $5 \mathrm{ml}$ of the $4 \%$ lidocaine solution. Fifteen femoral nerve blocks for the respective 15 patients were administered. All patients had complete blocks of the femoral nerve $(++\backslash++)$. The amount of lidocaine used to block the femoral nerve was 200 $\mathrm{mg}$. The solution of local anesthetic had spread in the fascial plane along the whole circumference of the femoral nerve.

Considering the fact that the amount of lidocaine at $200 \mathrm{mg}$ had sufficiently exceeded the minimal effective amount of lidocaine at the previous stages, which was $75 \mathrm{mg}$, we decided upon reducing the volume of the $4 \%$ lidocaine solution to $4 \mathrm{ml}(90 \mathrm{mg}), 3 \mathrm{ml}(120 \mathrm{mg})$ and $2.5 \mathrm{ml}(100 \mathrm{mg})$.

The aforementioned blocks were ineffective $(+\backslash+)$, so only 4 patients had such blocks. The solution of local anesthetic failed to spread into the fascial plane along the whole circumference of the femoral nerve. Subsequently, according to the Ethics Committee, blocks involving a volume of $4 \mathrm{ml}$, or less, of the $4 \%$ lidocaine solution were not administered.

The cross-sectional area of the femoral nerve was $0.24 \mathrm{~cm} 2$, and any statistically significant differences between the groups of patients were absent $(p=$ 0.99).

\section{Discussion}

In the course of our research, we have stated that the minimal effective amount of lidocaine necessary for a complete block of the femoral nerve was 75 mg. Additionally, the minimal volume of local anesthetic that spreads along the whole circumference of the femoral nerve was $5 \mathrm{ml}$. Previous literature has also suggested that the minimal volume of LA solution required to spread along the whole circumference of the sciatic nerve was $5 \mathrm{ml}$ [7]. The data acquired in our research were unexpected as the sciatic nerve is larger in its diameter than the femoral nerve. This may have been accounted for by the peculiarities in the structure of the fascial planes of both nerves; by the differences in the characteristics of the surrounding tissues; and by the pressure that these tissues exert on LA in the plane of the nerve. Nonetheless, these theories warrant further investigation.

The effective amount of $75 \mathrm{mg}$ of lidocaine was achieved only while applying $0.75 \%, 1 \%$ and $1.5 \%$ solutions. The volume acted as a limiting factor for other concentrations. Volumes of $4 \mathrm{ml}$, or less, of LA failed to spread along the whole circumference of the femoral nerve, and as a result, a complete block did not develop. 
While applying a volume of $7.5 \mathrm{ml}$ of the $1 \%$ lidocaine, we induced a complete block of the femoral nerve. When the volume of LA was reduced to $5 \mathrm{ml}$, the amount of lidocaine dropped to $50 \mathrm{mg}$. As had been similarly observed with the volume of $7.5 \mathrm{ml}(56.25 \mathrm{mg})$ of the $0.75 \%$ lidocaine solution, complete motor and sensory blocks failed to develop. In both cases, the amount of $75 \mathrm{mg}$ of lidocaine acted as a limiting factor. The applied volume of LA had spread along the whole circumference of the femoral nerve.

At other stages of the research $(1.5 \%, 2 \%, 3 \%, 4 \%)$, the effectiveness of the blocks had only developed after a volume of $5 \mathrm{ml}$, or more, of the LA. Furthermore, a complete femoral block failed to develop even after the application of a volume of $4 \mathrm{ml}$, or less, of LA solution, with concentrations of $2 \%, 3 \%$, and $4 \%$, in addition to the application of lidocaine solutions that contained more than $75 \mathrm{mg}$ (80, 120 and $160 \mathrm{mg}$ correspondingly). The volumes of LA at $4 \mathrm{ml}$, or less, did not spread along the whole circumference of the femoral nerve. Thus, the limiting factor of the effective block was in the volume of LA, and not in its amount.

Latzke et al. $[6,15]$ questioned the widely accepted theory that for an effective block, a complete spread of LA along the whole circumference of the nerve was not required. Nonetheless, these authors noted that in such cases, effective blocks developed in only $50 \%$ of the scenarios. 6 Furthermore, they did not assess motor blocks either [6].

Subsequently, data were published which suggested that incomplete spreading of LA along the whole circumference of the sciatic nerve resulted in only an incomplete sensory and motor block (even with an excessive amount of local anesthetic in the solution) [7]. In our research, we have stated that a complete block of the femoral nerve developed only with a complete spread of LA along the whole circumference of the femoral nerve. These data support the earlier, published information $[7,15]$.

Moayeri et al. $[14,16]$ noted that the conjunctive and adipose tissue of the peripheral nerves hinders the diffusion depth of LA into the nerve and towards the axons. Additionally, the lipid layer of the epineureum serves as a deposit for LA which leads to a decrease in the amount of LA available for diffusion into the neural tissue of the peripheral nerve. The assumption was that for the same nerve (the sciatic nerve and brachial plexus), an increase in the proportion of nonneural tissue at different places resulted in an increase in the effective amount of local anesthetic [14, 16].

It was assumed that the application of small doses of LA was affected by the different thicknesses of the femoral nerve. However, in our research, statistical differences in the cross-sectional area of the femoral nerve between the groups were absent, thereby minimizing the supposed influence of the correlation between neural and non-neural tissue on the minimal effective dose of LA $[14,16,17,18]$

With regards to the incomplete spread of LA along the whole circumference of the nerve, an increased distance between the location of LA administration, and the targeted area for diffusion in the peripheral nerve was observed. In such cases, the LA was insufficient to diffuse into all parts of the femoral nerve as "the target distance" for LA diffusion had increased (Fig. 5).

Figure 5 schematically shows the diffusion of LA during its spread along the whole circumference of the peripheral nerve, represented in (A), and its incomplete spread along the circumference of the nerve, represented in (B). On the basis of the data regarding the factors affecting the diffusion of local anesthetic published earlier $[14,16]$, as well as on the data indirectly supporting this literature, $[17,18]$ and those in current research, we assumed that in the case of (A), that a relatively even distribution of LA (c) occurs along the whole cross-section of the nerve, thereby completely blocking its action (with a sufficient amount of LA). In the case of (B) (Fig. 5), the distance for the diffusion of LA towards all sections of the nerve increases. Taking into account the barrier and lipid soluble characteristics of the conjunctive and lipid tissues of the epineurium, we assumed that the concentration, (c), of LA would be smaller in the distal nerve further along from the point of LA administration in the fascial plane. This was due to the LA failing to spread to this area (schematically referred to as "c", with a lower frequency as indicated in Picture 5). As we have indicated in this case, effective nerve blocks do not develop, or as indicated by earlier publications, may not always develop $[6,7,8,15]$. This warrants further investigations.

As Taha and Abd-Elmaksoud noted in their paper $[6,10]$ all data acquired from previous publications had indicated that for an effective block of a peripheral nerve required a cross-sectional area of $0.1 \mathrm{ml} \mathrm{mm}-2$. However, the research conducted by Taha and Abd-Elmaksoud failed to confirm this. Our research achieved results similar to those acquired by Latzke et al., [6] in comparison to the results achieved by Taha and Abd-Elmaksoud [10].

The ratio of ED50 to ED90, defined as ED50;90, would remain between 7.5 и $5 \mathrm{ml}$ for the $1 \%$ lidocaine solution, between 7.5 и $10 \mathrm{ml}$ for $0.75 \%$ lidocaine solution, and further for each concentration under analysis according to the results presented in Table 2.

There are several approaches to organize the research defining the minimal dose and volume of local anesthetic to perform peripheral nerve blocks. The method that Dixon[10] suggested in 1948, and its modified version, has allowed for the definition of ED50.

Another method stated that according to the effective concentration of LA, the following concentration of anesthetic either increases or decreases by $0.1 \%, 10$ and that, therefore, the minimal effective volume of local anesthetic had not yet been defined. Alternatively, one concentration of local anesthetic may be used, and prior to the investigation, a researcher chooses several LA volumes to perform the blocks [13]. From this, the possible ED is calculated.

Another method used to determine the minimal amount of LA for several concentrations was by sequentially reducing their volumes. The reduction in volume is defined by anesthesiologist according to the efficacy of the block with regards to the given amount of LA. The data are then listed in a table format. The necessity for further investigation is determined by different groups: the reduction in the volume; the decrease or increase in the concentration according to earlier results; and for the conveniences of everyday anesthesiology practice. This method has allowed for the definition of both the minimal effective amount of LA and the minimal effective volume of LA (while applying the proven, effective amount of LA) [7]. This method considers the doses and volumes to be ineffective if there is failure to develop a complete block upon introduction of the whole LA volume into the target area (fascial compartment). ED50, ED80, and ED90 are not assessed. The conclusion was that an effective volume and amount of a block with LA solution should induce complete peripheral blocks. If

Page 6/11 
a complete block does not develop, the amount and volume are considered to be ineffective. This method provides a good basis for recommendations as the LA amount and volume are only considered effective when they induce complete blocks of the peripheral nerve.

\section{Conclusion}

In the course of our research, we have indicated that the minimal effective volume of lidocaine necessary for the development of a complete block of the femoral nerve was $5 \mathrm{ml}$. The minimal amount of lidocaine necessary for the development of a complete block of the femoral nerve was $75 \mathrm{mg}$. In our research, a complete block of the femoral nerve was achieved only with the spreading of local anesthetic along the whole circumference of the femoral nerve.

Research limitations included the lack of a completely blinded trial, and the volumes of LA for the different concentrations achieving $5 \mathrm{ml}$, which were dropped by $1 \mathrm{ml}$ for sake of convenience in everyday anesthesiology. The BMI remained constant within narrow limits. Most likely, a larger number of patients in groups with ineffective blocks of the femoral nerve, relative to that of the number of effective blocks, was evident (the decision of the Ethics Committee).

A peculiarity of the research was that the volumes of lidocaine for the different concentrations were chosen according to the effective volume and amount of lidocaine stated at the previous stages.

In future, it is probably relevant to study other volumes of lidocaine (e.g. $4.5 \mathrm{ml})$ and apply the scheme in the study of other anesthetics.

\section{List Of Abbreviations}

local anesthetics (LA)

95\% effective dose (ED95)

$50 \%$ effective dose (ED50)

American Society of Anesthesiologists (ASA)

electrocardiography (ECG)

electrostimulation of the peripheral nerves (EPN)

neurostimulator (NS)

ultrasound (US)

\section{Declarations}

Ethical approval for this study was acquired by the Ethical Committee of the Mogilev Regional Hospital, Belarus (President Dr. Alexandr R. Stolin), Protocol No. 30 on 5 September 2011.

All patients received informed consent.

Consent to publish

Valeri Piacherski: I agree

Aliaksei Marachkou: I agree

-Availability of data and material. Materials are available from the author at:

In our hospital (as well as in our healthcare system), such a legal system is not yet available. In view of this, I can easily provide this data when contacting those interested in my email.

\section{pechersky.v@yandex.ru (pechersky.v@outlook.com)/}

No Conflict of Interest

Funding

Not applicable. The authors did not receive any funding. Relevant document submitted.

The authors contributions:

Valeri Piacherski (VP):

The study design, data collection, patient enrollment, perform anesthesia, ultrasound measurement of the femoral nerve, the analysis of results, writing the first version of the article 
Aliaksei Marachkou (AM):

The study design, the analysis of results, writing the first version of the article. conceived of the study, and participated in its design and coordination and helped to draft the manuscript.

All authors read and approved the final manuscript.

Acknowledgements-- Not applicable

Valery Piacherski Aliaksei Marachkou

\section{References}

1.Vanterpool S, Steele SM, Nielsen KC, Tucker M, Klein SM. Combined lumbar-plexus and sciatic nerve blocks: an analysis of plasma ropivacaine concentrations. Reg Anesth Pain Med 2006; 31: 417-421.

2.Cuvillon P, Nouvellon E, Ripart J, Boyer JC, Dehour L, Mahamat A, et al. A comparison of the pharmacodynamics and pharmacokinetics of Bupivacaine, Ropivacaine (with Epinephrine) and their equal volume mixtures with Lidocaine used for femoral and sciatic nerve blocks: A double-blind randomized study. Anesth Analg 2009; 108: 641-649.

3.Reinikainen M, Hedmlan A, Pelkonen O, Ruokonen E. Cardiac arrest after interscalene brachial plexus block with Ropivacaine and Lidocaine. Acta Anesthesiol Scand 2003; 47: 904-906.

4.Mather LE, Copeland SE, Ladd LA. Acute toxicity of local anesthetics: underlying pharmacokinetic and pharmacodynamic concepts. Reg Anesth Pain Med 2005; 30: 553-566.

5.Danelli G, Ghisi D, Fanelli A, Ortu A, Moschini E, Berti M, et al. The effects of ultrasound guidance and neurostimulation on the minimum effective anesthetic volume of Mepivacaine 1.5\% required to block the sciatic nerve using the subgluteal approach. Anesth Analg 2009; 109(5): 1674-1678.

6.Latzke D, Marhofer P, Zeitlinger M, A. Machata F. Neumann E. Lackner, et al. Minimal local anaesthetic volumes for sciatic nerve blockade: evaluation of ED99 in volunteers. Br J Anaesth 2010; 104: 239-244.

7.Piacherski V, Marachkou A. Features and principles the spread of local anesthetic blockade of the sciatic nerve at depends on the amount of anesthetic. Open J Anesthesiol 2014;4:31-35.

8.Piacherski V, Marachkou A. A comparison of the onset time of complete blockade of the sciatic nerve in the application of Ropivacaine and its equal volumes mixture with Lidocaine: A double-blind randomized study. Korean J Anesthesiol 2013; 65: 42-47.

9.Casati A, Baciarello M, Di Cianni S, Danelli G, De Marco G, Leone S et al. Effects of ultrasound guidance on the minimum effective anaesthetic volume required to block the femoral nerve. $\mathrm{Br} \mathrm{J}$ Anaesth 2007; 98: 823-827.

10.Taha AM, Abd-Elmaksoud AM. Lidocaine use in ultrasound-guided femoral nerve block: what is the minimum effective anaesthetic concentration (MEAC90)? Br. J. Anaesth 2013; 110(6): 1040-1044.

11.Dixon DJ, Mood AM. A method for obtaining and analysing sensitivity data. J Am Stat Assoc 1948; 43: 109-126.

12.Dixon WJ. The up and down method for small samples. J Am Statis Assoc 1965; 60: 967-978.

13.Gupta PK, Chevret S, Zohar S, Hopkins PM. What is the ED95 of prilocaine for femoral nerve block using ultrasound? Br. J. Anaesth 2013;110 (5):831-836.

14.Moayeri N, Groen GJ. Differences in quantitative architecture of sciatic nerve may explain differences in potential vulnerability to nerve injury, onset time, and minimum effective anesthetic volume. Anesthesiology 2009; 111: 1128-1134.

15.Kumar PA, Gentry WB, Arora H. Ultrasound Guidance in Regional Anaesthesia. J Anesth Clin Pharmacology 2007; 23(2): $121-128$.

16.Moayeri N, Bigeleisen PE, Groen GJ. Quantitative architecture of the brachial plexus and surrounding compartments, and their possible significance for plexus blocks. Anesthesiology 2008; 108: 299-304.

17.Piacherski V, Marochkov A, Brukhnou A, Kokhan Z. Comparison time development of the sciatic nerve blockade performed with $1 \%$ lidocaine subgluteal and popliteal approach under ultrasound guidance. Open J Anesthesiol 2014; 12: 231-236.

18.Taboada M, Alvarez J, Cortés J, Rodríguez J, Rabanal S, Gude F et al. The effects of three different approaches on the onset time of sciatic nerve blocks with $0.75 \%$ Ropivacaine. Anesth Analg 2004; 98: 242-247

\section{Tables}

Table 1. 


\begin{tabular}{|c|c|c|c|c|c|c|c|c|c|c|c|}
\hline $\begin{array}{l}\text { Characteristic } \\
\text { groups }\end{array}$ & $\begin{array}{l}1 \%- \\
20 \mathrm{ml}\end{array}$ & $\begin{array}{l}1 \%- \\
15 \mathrm{ml}\end{array}$ & $\begin{array}{l}1 \%- \\
10 \mathrm{ml}\end{array}$ & $1 \%-7,5 \mathrm{ml}$ & $\begin{array}{l}1 \%-5 \\
\mathrm{ml}\end{array}$ & $\begin{array}{l}0,75 \%- \\
10 \mathrm{ml}\end{array}$ & $\begin{array}{l}0,75 \%-7,5 \\
\mathrm{ml}\end{array}$ & $\begin{array}{l}1,5 \% \\
-5 \mathrm{ml}\end{array}$ & $\begin{array}{l}1,5 \%-4 \\
\mathrm{ml}\end{array}$ & $\begin{array}{l}2 \%-5 \\
\mathrm{ml}\end{array}$ & 2 \\
\hline $\begin{array}{l}\text { Number of } \\
\text { Patients }\end{array}$ & 15 & 15 & 15 & 20 & 4 & 20 & 4 & 15 & 4 & 15 & 4 \\
\hline Ages, years & $\begin{array}{l}42 \\
(25- \\
46)\end{array}$ & $\begin{array}{l}41 \\
(37- \\
39)\end{array}$ & $\begin{array}{l}42(28 \\
-49)\end{array}$ & $\begin{array}{l}42(26- \\
55)\end{array}$ & $\begin{array}{l}36(28- \\
40)\end{array}$ & $\begin{array}{l}44(21- \\
51)\end{array}$ & $\begin{array}{l}39(31,5- \\
48)\end{array}$ & $\begin{array}{l}45 \\
(38- \\
39)\end{array}$ & $\begin{array}{l}35(30- \\
39.5)\end{array}$ & $\begin{array}{l}44(37 \\
-51)\end{array}$ & $\begin{array}{l}3 \\
4\end{array}$ \\
\hline BMI & $\begin{array}{l}25 \\
(23- \\
27)\end{array}$ & $\begin{array}{l}25 \\
\text { (23- } \\
27)\end{array}$ & $\begin{array}{l}24(22- \\
27)\end{array}$ & $\begin{array}{l}25.75(23.5- \\
28)\end{array}$ & $\begin{array}{l}23(20.5- \\
25.5)\end{array}$ & $\begin{array}{l}27(24.75- \\
27.75)\end{array}$ & $\begin{array}{l}23.25(21.5- \\
24.75)\end{array}$ & $\begin{array}{l}24.5 \\
(22- \\
27)\end{array}$ & $\begin{array}{l}25.5(23- \\
26.5)\end{array}$ & $\begin{array}{l}25(22- \\
27)\end{array}$ & $\begin{array}{l}2 \\
2\end{array}$ \\
\hline $\begin{array}{l}\text { Gender (m / } \\
\text { f) }\end{array}$ & $10 / 5$ & $7 / 8$ & $9 / 6$ & $12 / 8$ & $4 / 0$ & $15 / 5$ & $3 / 1$ & $7 / 8$ & $1 / 3$ & $12 / 3$ & $0 /$ \\
\hline $\begin{array}{l}\text { The cross } \\
\text { sectional area } \\
\text { of the femoral } \\
\text { nerve, } \mathrm{sm}^{2}\end{array}$ & $\begin{array}{l}0.25 \\
(0.24- \\
0.3)\end{array}$ & $\begin{array}{l}0.27 \\
(0.24- \\
0.3)\end{array}$ & $\begin{array}{l}0.27 \\
(0,24- \\
0,3)\end{array}$ & $\begin{array}{l}0.26(0.23- \\
0.3)\end{array}$ & $\begin{array}{l}0.26 \\
(0.24- \\
0.28)\end{array}$ & $\begin{array}{l}0.27 \\
(0.24- \\
0.28)\end{array}$ & $\begin{array}{l}0.26(0.22- \\
0.3)\end{array}$ & $\begin{array}{l}0.26 \\
(0.25- \\
0.28)\end{array}$ & $\begin{array}{l}0.26 \\
(0.23- \\
0.3)\end{array}$ & $\begin{array}{l}0.25 \\
(0.23- \\
0.29)\end{array}$ & $\begin{array}{l}0 \\
(1 \\
0\end{array}$ \\
\hline
\end{tabular}

Table 2.

\begin{tabular}{|c|c|c|c|c|c|c|}
\hline \multirow[t]{2}{*}{ Volume of solution, $\mathrm{ml}$} & \multicolumn{6}{|c|}{ Concentration of lidocaine solution, $\%$} \\
\hline & 0,75 & 1 & 1,5 & 2 & 3 & 4 \\
\hline 20 & & $\begin{array}{l}200 \mathrm{mg} \\
\mathrm{N}=15\end{array}$ & & & & \\
\hline 15 & & $\begin{array}{l}150 \mathrm{mg} \\
\mathrm{N}=15\end{array}$ & & & & \\
\hline 10 & $\begin{array}{l}75 \mathrm{mg} \\
\mathrm{N}=20\end{array}$ & $\begin{array}{l}100 \mathrm{mg} \\
\mathrm{N}=15\end{array}$ & & & & \\
\hline 7,5 & $\begin{array}{l}56.25 \mathrm{mg} \\
\mathrm{N}=4\end{array}$ & $\begin{array}{l}75 \mathrm{mg} \\
\mathrm{N}=20\end{array}$ & & & & \\
\hline 5 & & $\begin{array}{l}50 \mathrm{mg} \\
\mathrm{N}=4\end{array}$ & $\begin{array}{l}75 \mathrm{mg} \\
\mathrm{N}=15\end{array}$ & $\begin{array}{l}100 \mathrm{mg} \\
\mathrm{N}=15\end{array}$ & $\begin{array}{l}150 \mathrm{mg} \\
\mathrm{N}=15\end{array}$ & $\begin{array}{l}200, g \\
N=15\end{array}$ \\
\hline 4 & & & $\begin{array}{l}60 \mathrm{mg} \\
\mathrm{N}=4\end{array}$ & $\begin{array}{l}80 \mathrm{mg} \\
\mathrm{N}=4\end{array}$ & $\begin{array}{l}120 \mathrm{mg} \\
\mathrm{N}=4\end{array}$ & $\begin{array}{l}160 \mathrm{mg} \\
\mathrm{N}=4\end{array}$ \\
\hline 3 & & & & & $\begin{array}{l}90 \mathrm{mg} \\
\mathrm{N}=4\end{array}$ & $\begin{array}{l}120 \mathrm{mg} \\
\mathrm{N}=4\end{array}$ \\
\hline 2,5 & & & & & & $\begin{array}{l}100 \mathrm{mg} \\
\mathrm{N}=4\end{array}$ \\
\hline
\end{tabular}

. Reference to table 2. The black color marks the columns listing the groups where complete sensory and motor blocks of the femoral nerve had developed. $\mathrm{N}$ represents the number of patients. The groups with complete sensory and motor blocks of the femoral nerve are marked in black. $\mathrm{N}$ - the number of patients.

\section{Figures}




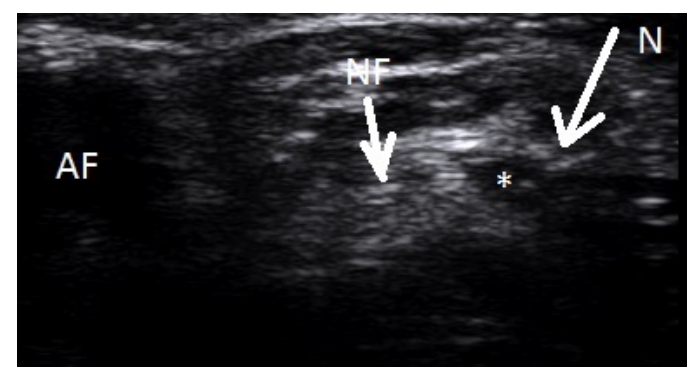

Figure 1

Start of local anesthetic AF - the femoral artery; NF - the femoral nerve; The white line circled the femoral nerve $\mathrm{N}$ - the needle under the femoral nerve (in plane)*- local anesthetic.

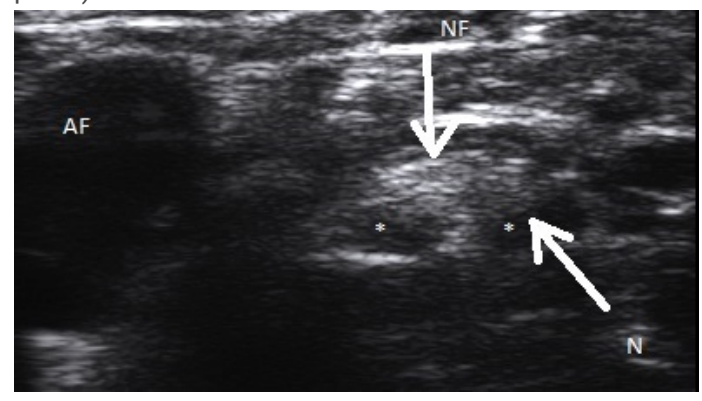

\section{Figure 2}

$\mathrm{AF}$ - the femoral artery; NF - the femoral nerve; The white line circled the femoral nerve $\mathrm{N}$ - the needle above the femoral nerve (in plane) * - local anesthetic. Yellow line encircles local anesthetic

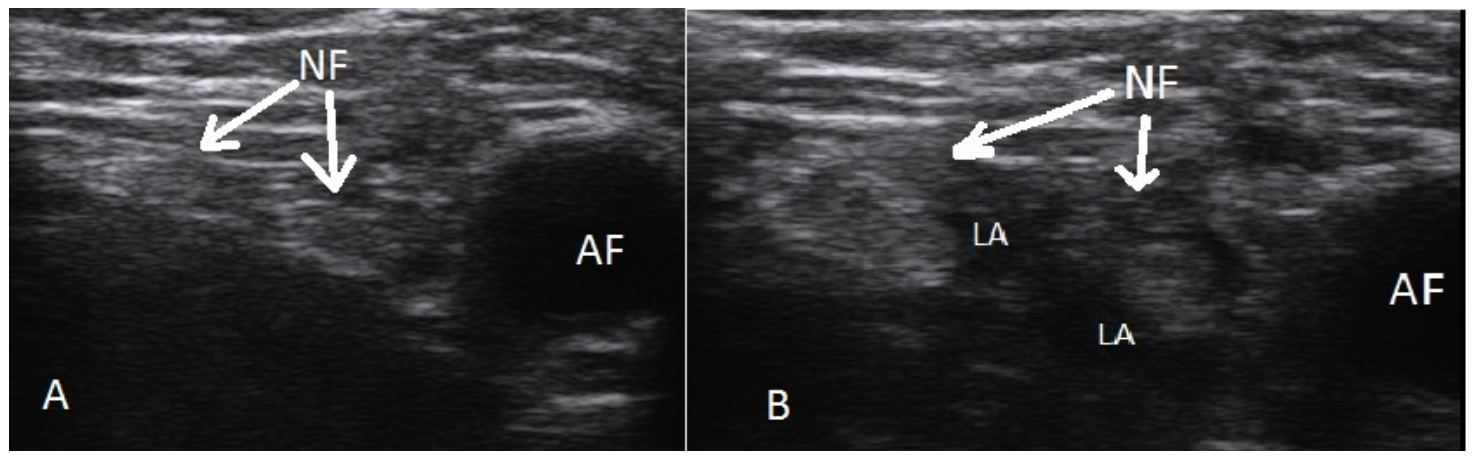

\section{Figure 3}

A - the femoral nerve before the introduction of local anesthetic. Two visualized trunks are indicated with arrows; B - the femoral nerve during the introduction of local anesthetic. The local anesthetic is spreading towards the trunks of the femoral nerve; AF - the femoral artery; NF - the femoral nerve; LA - local anesthetic. The white line circled the trunks of the femoral nerve. Yellow line encircles local anesthetic

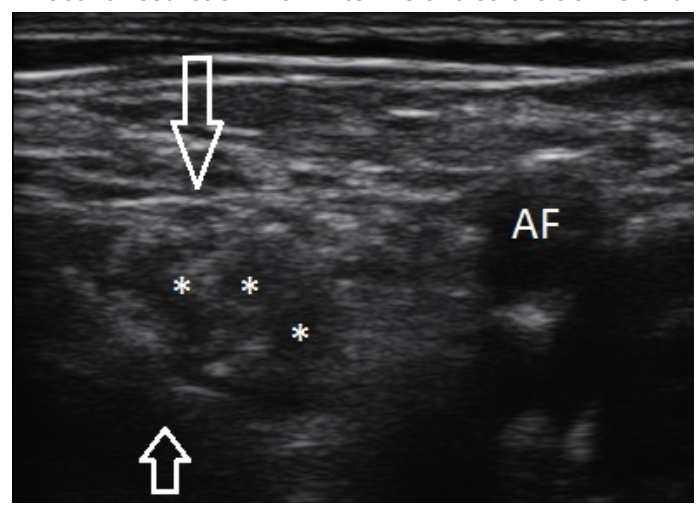

\section{Figure 4}

AF - the femoral artery. *- local anesthetic intraneurally. The white line circled the femoral nerve 


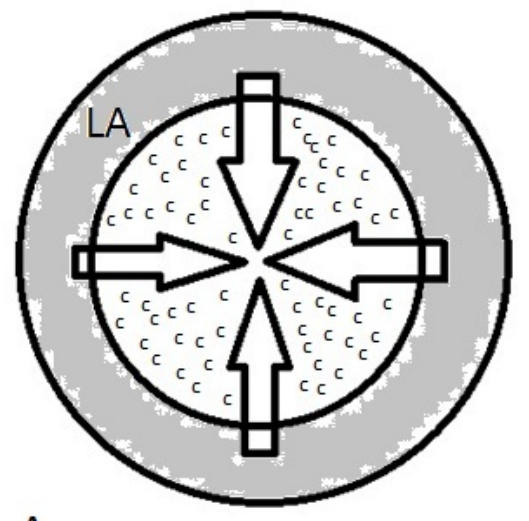

A

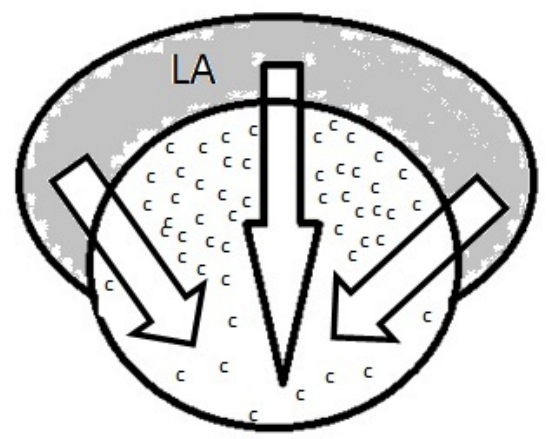

B

\section{Figure 5}

A - The anesthetic spread around the entire circumference of the peripheral nerve. B - The anesthetic has not spread around the entire circumference of the peripheral nerve. Arrows - the direction of diffusion of the local anesthetic into the nerve (schematically) LA - Local anesthetic around the nerve. C - schematic distribution of the concentration of the local anesthetic in the nerve - a higher frequency " $\mathrm{C}$ " indicates a high concentration of local anesthetic in the peripheral nerves (schematically). 